\title{
Coagulase-negative staphylococci (CoNS) as a significant etiological factor of laryngological infections: a review
}

\author{
Michał Michalik', Alfred Samet ${ }^{1}$, Adrianna Podbielska-Kubera' ${ }^{1}$, Vincenzo Savini ${ }^{2}$, Jacek Międzobrodzki ${ }^{3}$ \\ and Maja Kosecka-Strojek ${ }^{3^{*}}$
}

\begin{abstract}
This review article shows that coagulase-negative staphylococci (CONS) are widely responsible for laryngological diseases. General characteristics of CoNS infections are shown in the introduction, and the pathogenicity in terms of virulence determinants, biofilm formation and genetic regulation mechanisms of these bacteria is presented in the first part of the paper to better display the virulence potential of staphylococci. The PubMed search keywords were as follows: CoNS and: nares infections, nasal polyps, rhinosinusitis, necrosing sinusitis, periprosthetic joint infection, pharyngitis, osteomyelitis of skull and neck bones, tonsillitis and recurrent tonsillitis. A list of laryngological infections and those related to skull and neck bones was presented with descriptions of the following diseases: rhinosinusitis, necrotizing sinusitis, nasal polyps, nares and nasal skin infections, periprosthetic joint infections, osteomyelitis, pharyngitis, and tonsillitis. Species identification and diagnostic problems challenging for diagnosticians are presented. Concluding remarks regarding the presence of CoNS in humans and their distribution, particularly under the effect of facilitating factors, are mentioned.
\end{abstract}

Keywords: Coagulase-negative staphylococci, CoNS, Infections, Laryngology, Staphylococcus

\section{General characteristics of coagulase-negative staphylococci (CoNS) infections}

The significance of CoNS in infectious medicine became apparent in the late 1970s following a series of articles on the isolation of these bacteria from diagnostically documented infections in humans, as shown by several authors [1-6]. The definition of CoNS as a heterogeneous group of staphylococci is based on diagnostic procedures that fulfil the clinical need to differentiate between Staphylococcus aureus, commonly known as strongly pathogenic, and other staphylococci classified as non- or less pathogenic [7]. CoNS are characterized by fewer virulence factors than $S$. aureus, especially factors

*Correspondence: maja.kosecka-strojek@uj.edu.pl

${ }^{3}$ Department of Microbiology, Faculty of Biochemistry, Biophysics and Biotechnology, Jagiellonian University, Kraków, Poland

Full list of author information is available at the end of the article responsible for aggression, so they are considered less pathogenic. However, the virulence of both CoNS and coagulase-positive staphylococci (CoPS), represented by S. aureus, were compared using various animal models of experimental infections [8-13]. The authors showed that some CoNS species demonstrated skin lesions similar to the lesions generated by S. aureus [11]. Generally, the pathogenic potential of CoNS could be accepted when both biochemical and genetic molecular methods were introduced to analyze the pathogenesis and mechanisms of infections [7, 14]. In the last two decades, the medical importance of this group of bacteria has increased, as reported by clinicians and microbiologists $[15,16]$. There is evidence that CoNS are responsible for a variety of infections that differ in localization, manifestation or course of infection. However, staphylococcal bacteria are opportunistic pathogens that are present in the skin and mucous membranes of healthy individuals and become 
true pathogens mostly for predisposed patients, i.e., immunocompromised individuals, patients with catheters, prosthetic implants, dialysis, and oncological diseases, and neonates [17-20].

As pathogens, CoNS are involved in a broad range of diseases in deep organs, including bones, the central nervous system, the heart or joints [21]. However, CoNS are typical opportunistic bacteria that not only colonize healthy individuals but also represent one of the major hospital pathogens with a substantial increasing impact on human life and health [7]. The presence of CoNS in the skin and mucous membranes of the host is a main source of endogenous infections [7, 22]. In addition, bacteria are transmitted among diverse hosts by crossing species barriers and during medical procedures, especially invasive ones [23, 24]. Regarding otorhinolaryngology, CoNS are always present in the skin and mucous membranes of the nose, respiratory tract, oral cavity and alimentary canal $[25,26]$. In the field of laryngology, the main papers on CoNS pathogenicity focus on diseases such as bacteremia, septicemia, pneumoniae, endocarditis or urinary tract infections, but there are few reports on laryngological diseases such as rhinosinusitis and sinusitis, both acute and chronic, and infections of the frontal sinus, throat, larynx, nares, polyps, tonsils, and trachea. A dozen of the over 50 described CoNS species have been commonly reported in these diseases, including Staphylococcus epidermidis, Staphylococcus haemolyticus, Staphylococcus lugdunensis, Staphylococcus warneri, Staphylococcus xylosus, Staphylococcus hominis, Staphylococcus capitis, Staphylococcus simulans, Staphylococcus sciuri, Staphylococcus cohnii, Staphylococcus lentus, and Staphylococcus chromogenes, although other rare species, such as Staphylococcus pettenkoferi, have been documented $[7,27,28]$.

\section{Pathogenicity: virulence determinants, biofilm formation and genetic regulation of CoNS species}

CoNS possess numerous diverse strategies to both cause infection and survive in the host. In comparison to $S$. aureus, this group of bacteria exhibits lower pathogenic potential, but less is known about CoNS virulence mechanisms. Recent studies have focused on the ability of CoNS to produce a variety of extracellular enzymes, such as proteases, elastases, esterases, lipases, and phospholipases [29-32], as well as the production of toxins, such as families of hemolysins, enterotoxins, exfoliative toxins, and even TSST-1 (Toxic shock syndrome toxin-1) [7, 3336]. The enzymes and toxins presented play crucial roles in some of the effects of staphylococci on host organisms, including virulence factors in tissue destruction and additionally as spreading factors facilitating invasion into nearby tissues. In general, CoNS species lack the virulence determinants responsible for aggression, but they possess the ability to adhere, invade and persist $[14,31]$. Furthermore, a critical CoNS property is the ability to colonize the surfaces of medical devices by the formation of a three-dimensional structured matrix composed of bacteria and extracellular biopolymers-biofilm. Increasing evidence suggests that biofilms may form on abiotic surfaces of medical devices or on biotic surfaces, such as host factor-coated foreign material or host tissue $[37,38]$. Biofilm-associated infections are extremely difficult to eradicate because within the biofilm, bacteria are protected against the immune system of the patient and antibiotic therapy $[39,40]$. Identification of the factors that increase CoNS pathogenicity is a great need, especially for clinicians and microbiologists. Studies described to date have demonstrated that $S$. epidermidis isolates differ regarding antibiotic resistance gene acquisition (e.g., SCCmec), biofilm forming capacities (e.g., ica locus), metabolism (e.g., arginine catabolic mobile element ACME) and the presence of insertion sequence (IS) elements (e.g., IS256) [41-44]. It is very important to extend such studies to a larger number of isolates and species, but there is strong evidence that horizontal gene transfer is responsible for virulence factor transmission between species [45-48]. Staphylococcal pathogenesis is a process involving an array of extracellular proteins and biofilm and cell wall components that are coordinately expressed in different phases of infection. The expression or suppression of two divergent loci, accessory gene regulator (agr) and staphylococcal accessory regulator (sar), are recognized as key regulators of virulence in staphylococcal infections $[49,50]$. The agr system is known to modulate virulence factors such as nucleases, proteases, lipases and the expression of surface binding proteins, and sar can modulate both the agr system and independently form an $a g r$ locus of cell wall-associated proteins such as fibronectin-binding protein, adhesins, protein-A and exo-proteins. When the bacterial population is low, the expression of adherence proteins is triggered for attachment to host tissue and toxins are produced once the infection is established [51].

\section{General descriptions of laryngological infections}

Laryngology, otolaryngology, is generally a broad medical discipline that covers the diagnosis, therapy, and prophylaxis of diseases of the upper respiratory tract and additional organs present in the neck and head, including throat, larynx, nose, ears, and other organs in these parts of body [52]. Recently, important medical questions in laryngology have been raised regarding oncological and infectious diseases [53, 54]. Statistically viral and bacterial infections of the respiratory tract that spread into other anatomical niches are the most identified 
in epidemiological analysis. Staphylococci, particularly CoNS, can cause local infections, but they are also responsible for pathological complications after expanding from laryngological areas to other areas, including skin, and heart, and even sepsis in newborns as well as nosocomial infections [55-61]. Moreover, an increasing number of fungal infections has recently been reported in laryngology studies, and these infections are related to the overconsumption of antibiotics and patients with immune disorders.

\section{Rhinosinusitis}

The rhinosinus is the space in the front part of the facial skeleton that is filled with air and mucous membranes with ciliated epithelium, including mucous glands. In addition, inflammation proceeds synchronously because of the anatomical and physiological relations of the mucous membranes of the nose and rhinosinus, which is the reason for the Latin name used for inflammation of mucous membranes of nose and rhinosinus-rhinosinusitis. Acute rhinosinusitis (ARS) appears the most frequently in the course of viral cold disease, whereas chronic rhinosinusitis (CRS) is a common source of CoNS isolation [62]. CRS represents a heterogeneous group of diseases resulting from the multifaceted interactions between the individual patient and environment. Chronic rhinosinusitis is one of the most common chronic disorders, present in up to $28 \%$ of European or American populations [63]. The mechanisms of this disease are still under careful molecular analysis. The main underlying causes of rhinosinusitis are various bacteria, but the most commonly isolated are gram-positive cocci. The predominant organisms identified are streptococci and staphylococci. Bacterial infection plays an important role in CRS as either a causative or exacerbating factor $[64,65]$. However, the role of CoNS in CRS remains "controversial" [66]. For a significant subpopulation of patients, only CoNS were isolated, while another population had other positive cultures, and a small group had no bacterial growth [66].

Microbiological analysis of samples from CRS patients revealed that mainly CoNS were identified, followed by $S$. aureus and gram-negative rods, including Pseudomonas aeruginosa, Stenotrophomonas maltophilia, Escherichia coli, and Serratia marcescens [65]. The most frequently found CoNS species in CRS patients was S. epidermidis, and other CoNS, such as S. lugdunensis, S. capitis, Staphylococcus saprophyticus, S. haemolyticus, and Staphylococcus saccharolyticus and to a lesser degree other minor CoNS, were present in $87 \%$ of cases [63, 67].

Molecular genetic studies have shown that the pathologic ability of CoNS such as S. epidermidis depends on genes associated with biofilm formation that have only been found in certain strains [68]. However, knowledge of the importance of bacteria and microbial biofilms in the etiology of CRS is still incomplete. Some authors have determined the association between positive CoNS culture at the time of functional endoscopic sinus surgery (FESS) and CRS severity. Simultaneously, bacteria other than CoNS have been isolated: Streptococcus pneumoniae (30-70\%), Streptococcus pyogenes (3-7\%), Streptococcus spp., Moraxella catarrhalis (12-28\%), Enterobacter spp., Cutibacterium acnes [66], S. aureus (27\%), Haemophilus influenzae (27\%), P. aeruginosa (22\%), Peptostreptococcus spp. (20\%), Bacteroides spp. (19\%), Klebsiella pneumoniae (11\%), and E.coli (11\%) [69]. Other authors analyzed the exacerbation of CRS in 125 patients and identified CoNS as the most common organism, followed by S. aureus [70]. Studies on cultures from 394 CRS patients revealed that aerobes were predominant, and CoNS were common (24\%), followed by S. aureus (19\%) and Streptococcus viridans (10\%) [71]. Despite the high prevalence of CoNS and their controversial effect on CRS, some reports have shown that the bacteria as the sole positive culture result did not result in increased CRS disease burden [66]. The presence of CoNS alone was independently associated with no history of prior FESS. However, some authors showed no significant difference in CRS disease severity between patients with CoNS as the sole positive culture result and no bacterial growth, but phenomena such as horizontal virulence gene transfer, quorum sensing, and mechanisms of gene expression/suppression necessitate further studies on a larger number of patients and isolates to evaluate whether the effect of CoNS differs in various subgroups $[66,69]$. The role of CoNS in CRS pathogenesis is not completely understood because the bacteria that colonize the nasal cavity under physiological conditions have been interpreted as contamination in microbiological analysis by few authors. Most authors have reported an important role for CoNS in CRS pathogenesis and the mechanism of the disease because of the extracellular production of virulence factors such enzymes and toxins, biofilm formation, and virulence or resistance gene transfer among the bacteria colonizing these anatomical areas. However, there are few factors that may affect the detection of CoNS as etiological factors in such infections. The frequency of CoNS isolation at the infection site and the molecular typing of CoNS to determine the clonality of the isolates is crucial in determining the real etiological factor. Moreover, the presence of invasive medical devices and the immune status of patients should be considered, as immunocompromised patients are more susceptible to CoNS infection. 


\section{Necrotizing sinusitis}

Necrosing sinonasal infection often involves infectious agents such as viruses, bacteria, fungi, and parasites [7274]. However, the only reported CoNS species responsible for acute necrotizing sinusitis is S. lugdunensis, which was reported in hospitalized patients with metastatic prostate adenocarcinoma [75]. Additionally, severe acute necrotizing sinusitis was complicated by periorbital cellulitis and ulceration from the maxillary sinus to the hard palate. The only pathogen to be identified in three independent biopsy samples was $S$. lugdunensis [75]. The species identification of organisms was verified by the Health Protection Agency Respiratory and Systematic Infection Reference Laboratory using advanced methodology. Interestingly, S. lugdunensis, in addition to being a skin commensal of the limbs, groin and nose vestibule of healthy adults, has also been isolated from acute oral infections [76], prosthetic joints, endovascular, skin and soft tissue infections; in individual cases, S. lugdunenesis has been isolated as an agent of osteomyelitis, which can lead to laryngological implications in terms of significant effects on the head or face bones. Moreover, S. lugdunensis is a major pathogen for heart valves, both native and prosthetic, as it causes very aggressive endocarditis [75, 77].

\section{Nasal polyps}

Many staphylococci colonize the human nose vestibule; however, the main question relates to $S$. aureus, as it is unknown whether and how this bacterium adapts to this particular ecological niche during colonization. Staphylococci are among the bacterial species associated with increasing invasive diseases and drug resistance distribution in humans [78]. The analysis of the composition of the human nasal culturome revealed that S. epidermidis colonizes almost all individuals (97\%), followed by S. haemolyticus (44\%), S. hominis and S. capitis (each 41\%), S. warneri (32\%) and S. lugdunensis (26\%) [79]. The basis of colonization with strains carrying virulence determinants and/or resistance results from fibronectin-, fibrinogen-, and collagen-binding surface proteins responsible for adhesion and further infection [80]. Polyps are abnormal growth tissue complexes that originate from mucous membranes and are generally present in any organ. In laryngology, polyps are interpreted as disorders or lesions of an inflammatory nature or caused by injury; most cases involve a history of trauma [81]. Therefore, polyps occur elsewhere in the body where there is a mucous membrane. The presence of polyps and accompanying mucosal edema is one of the main observations at examination [82]. The polyps may be involved in chronic sinusitis. CRS with polyps can be present not as a single disease entity but as nasal symptoms of many different diseases [83]. Environmental microorganisms affect the host and cause symptoms in CRS. Bacteria involved in the disease play an important role, and bacterial biofilms present in CRS patients are responsible for noneffective therapy even after surgical and antibiotic interventions [63]. A group of patients with nasal polyps may have different disease etiologies, and it is well documented that culture results are difficult in postESS patients. CRS patients with CoNS as the sole positive culture result were significantly more likely to have nasal polyps [66]. Analysis of the bacteriological profile of the patients showed that CoNS, S. aureus, Streptococcus sp., Haemophilus sp., Enterobacter sp., and Corynebacterium sp. appear to be more frequently associated with patients with chronic rhinosinusitis (CRS) with nasal polyps than with patients with CRS without nasal polyps or control individuals, where the most common aerobic bacteria were CoNS, Corynebacterium spp., S. aureus, and $H$. influenzae. Additionally, few anaerobic bacteria and fungi have been isolated from various study groups [84]. Authors of another project reported no significant differences in isolation rates among three groups of CRS patients, i.e., with polyps, without polyps, and the control group, although the two most common bacterial species were CoNS and Corynebacterium spp. in CRS with polyps group; CoNS, Corynebacterium spp., and S. aureus in CRS without polyps group; and CoNS, and S. aureus in the control group. Finally, CoNS were the most common species among the three groups [85].

\section{Nares and nasal skin infections}

The human nares and skin flora are normally largely composed of different species of CoNS and coryneforms, as reported by many authors [1, 2, 86-88]. Among all aerobic bacteria, CoNS are the group of organisms with the best characteristics for growth and multiplication in cutaneous recesses enriched with sebum and sweat because of the many extracellular enzymes they produce, enabling the use of skin substrates, particularly neutral fatty acids of sebum [89-91]. Infections with Staphylococcus bacteria can result in a variety of skin conditions, including cellulitis, furuncles, impetigo or staphylococcal scalded skin syndrome (SSSS). Some CoNS strains, such as S. epidermidis and S. haemolyticus, share the same habitats as $S$. aureus and permanently or transiently colonize the anterior nares, nose vestibule, and other regions of skin and mucous membranes, acting as a source of infection [92]. Therefore, both S. aureus and CoNS are often recovered from the same diagnostic specimen in parallel [93].

CoNS infections of nares or nasal skin have been reported in a minority of cases in comparison to $S$. 
aureus infections, and they are always combined with immunocompromised or directly post-surgery hospitalized patients [94, 95]. Common types of nasal staphylococcal infections include folliculitis, which is an infection of one or many hair follicles; furuncle, also known as boils, which are deep infections around the hair follicle or oil glands that contain pus; or nasal vestibulitis, an infection of the front area of the nasal cavity that may cause crusting and bleeding. There are various symptoms of nasal staphylococcal infections, such as crusting, swelling, lesions with pus secretion, light bleeding, pain, redness or fever [96]. Therefore, nasal carriage of CoNS, especially methicillin-resistant CoNS, appears to play a key role in the epidemiology and pathogenesis of infections in nares or upper respiratory tracts [94]. Increasing evidence suggests that nasal CoNS are also reservoirs for mupirocin resistance, which may therefore be transmitted to S. aureus. Mupirocin is the first-line drug treatment to eradicate $S$. aureus nasal colonization, which may fail, although rarely, due to the transfer of underlying genetic elements from CoNS to S. aureus [97, 98]. Over the last few years, CoNS have become important as causative agents of hospital-acquired bacteremia and surgical site infections. Thus, CoNS colonizing anterior nares and skin are severe pathogens responsible for infections and are additionally often associated with multiple antimicrobial-resistance mechanisms, including antibiotic resistance of various other pathogens $[51,52]$.

\section{Periprosthetic joint infections}

In laryngology, temporomandibular joint (TMJ) infections are still a challenge, because there is no single leading disease [99]. The TMJ joins the mandible with the skull, and pain can mimic infections of the inner ear. The TMJ is part of a larger system known as the stomatological system or locomotor system of the masticatory apparatus. This is a very complex system under permanent and dynamic changes throughout life. Infections of the TMJ in both intracapsular and pericapsular courses are rare diseases [100]. The predisposing factors for contributing to TMJ infections are divided into local factors, such as blunt trauma, history of joint diseases and burn, and systemic factors including autoimmune disease and overconsumption of medicines with special reference to steroids $[57,101,102]$. Therefore, there are various reasons for TMJ infections; however, it is difficult to indicate the most important. Some authors have shown fatigue of TMJ muscles, orthodontic disorders, trauma of the head or spine, and stress as reasons for TMJ infections [103]. Analysis of ankylosis and arthritis showed that the most common causes of the disease are trauma and infection [104], and psychological aspects have also been reported as factors in nonorganic TMJ dysfunction [105].
The invasion of bacteria into the joint space can occur through several routes, but hematogenous spread indicates that blood circulation is the most common route. The other methods are adjacent, contiguous infected tissues and direct centesis into the joint cavity by direct inoculation [100]. Among these, the most prevalent route is hematogenous spread originating from primary infection sites [106]. The typical bacteria causing TMJ infections are Streptococcus spp., S. aureus, S. epidermidis, Neisseria gonorrhoeae, $H$. influenzae, and P. aeruginosa $[107,108]$. The tests used to confirm species identifications showed that CoNS, such as S. lugdunensis, S. epidermidis, S. haemolyticus, S. xylosus, S. warneri, and S. hominis, were isolated from fluid secreted by the temporomandibular joint of patients with muscle pain [109]. Additionally, S. capitis, a multidrug-resistant strain with documented potential for both human disease and nosocomial spread, was isolated from a group of patients [110]. An accompanying chronic orofacial muscle pain is associated with membrane-damaging toxins from CoNS (MDT-CoNS) or S. aureus. Previous reports suggest that membrane-damaging toxins produced by CoNS are associated with the development of chronic disease [111, 112]. Additionally, an evaluation in the distribution of Staphylococcus spp. in different phases of prosthetic joint infection (PJI) was observed, and the predominant pathogens were CoNS followed by S. aureus. Almost equal proportions of CoNS and S. aureus were observed in the delayed phase. CoNS were the predominantly identified organisms in the early phase, whereas $S$. aureus was observed primarily in the late phase [113]. In many medical disciplines, such as infectious laryngology, orthopedic infections due to CoNS presenting antibiotic-resistant profiles are increasing. Soft tissues and bone implantassociated infections are caused by CoNS, with the most prevalent species being $S$. epidermidis. These infections are considered difficult to treat because of the ability of the bacteria to grow in biofilms and form small-colony variants, including persistent organisms $[114,115]$.

\section{Osteomyelitis}

The discipline of laryngology also concerns diseases of the skull and neck bones. Osteomyelitis generally refers to laryngology-related inflammatory diseases of bones caused by microorganisms and leads to bone destruction. The most frequent microorganisms isolated from osteomyelitis are S. aureus and CoNS, with a predominance of $S$. epidermidis [116]. However, a new CoNS species, $S$. pettenkoferi, has been described as causing human osteomyelitis [117]. The disease otitis or otitis externa can also cause complications such as skull base osteomyelitis (SBO) [118]. In particular, orthopedic devices are used for bone fixation or joint replacement and are receptive/ 
susceptible to commensal bacteria, mainly CoNS. The therapy of such infections is expensive, and the infections result in high patient morbidity [119]. Bone infections caused by CoNS are associated with a high prevalence of methicillin resistance, and broad spectrum oral antibiosis was demonstrated in a predominantly diabetic population [116]. In advanced laryngology concerning surgical reconstructions of bones and/or accompanying soft tissues, infections due to CoNS and methicillin-resistant strains are increasing [114]. CoNS are often responsible for cases of chronic osteomyelitis and otitis, especially in patients with orthopedic prostheses or implants. Chronic courses of osteomyelitis or ostitis were caused by the following CoNS species: S. epidermidis, S. haemolyticus, S. simulans, S. warneri, S. sciuri, S. cohnii, S. hominis, S. lentus, S. chromogenes, and S. pettenkoferi [120]. Additionally, other chronic forms of osteomyelitis such as suppurative osteomyelitis of the jaws are caused by various bacteria, with a significant portion being CoNS [121].

\section{Pharyngitis, throat infection}

Pharyngitis is a disease of the throat, infection and inflammation caused by viruses, eubacteria, or Mycoplasma pneumoniae. The bacteria, that cause these infections include group A/C/G/B streptococci, Fusobacterium, and $N$. gonorrhoeae, but Str. pyogenes and other streptococci are the predominant species [52]. CoNS are generally considered nonpathogenic, and their presence in clinical material has been interpreted as contamination by normal microbiota present in the mucous membranes of the oral cavity and upper respiratory tracts. However, there are few reports on CoNS in cultures from throat infections, but these studies were mostly in children, and the role of CoNS as causative agents should be further investigated [122-124].

Tonsillitis (T) and recurrent tonsillitis (RT) are caused by viruses, bacteria, Chlamydia and fungi. The symptoms of tonsillitis and pharyngitis are similar. The most frequently isolated organisms from $\mathrm{T}$ or RT are $S$. aureus strains, from $70 \%$ of patients, followed by Streptococcus sp. from groups A, B, and C (and G), and the following species dominant as well: beta-hemolytic Str. pyogenes, H. influenzae, Haemophilus parainfluenzae, Klebsiella pneumoniae, Klebsiella oxytoca, Moraxella catarrhalis, Citrobacter koseri, Enterobacter cloacae, Enterobacter aerogenes, E. coli, and P. aeruginosa [125-127]. Aside from streptococci, all other species are considered able to colonize the throat and could be found in recurrent tonsillitis due to gastroesophageal reflux. CoNS have also been isolated in cultures from $\mathrm{T}$ and $\mathrm{RT}$ infections, but they are reported as accompanying bacteria and culture contaminants $[128,129]$. Such results and the involvement of S. aureus in the etiology of T and RT have not yet been fully understood because CoNS and occasionally $S$. aureus constantly colonize mucous membranes of the oral cavity and upper respiratory tracts. Furthermore, staphylococcal internalizations in deeper layers or even inside of tonsils, as well as in single cells of patients, have been observed $[125,130]$.

\section{Species identification and diagnostics problems}

Challenging identification processes may lead to a lack of noted infections caused by staphylococci other than $S$. aureus and their spread in the environment. Commonly used routine diagnostic methods, such as culture-dependent phenotypic tests, including automated systems such as Vitek 2 (bioMérieux, La Balme Les Grottes, France), BD Phoenix (BD Diagnostic Systems, Sparks, MD, USA), and matrix-assisted laser desorption ionization-time of flight mass spectrometry (MALDITOF MS), both with 16S rRNA gene sequencing, are usually not precise enough to carefully assign Staphylococcus species [28, 131-134]. Many members of the Staphylococcus genus are closely phylogenetically related, and the real impact of CoNS species as infectious etiological factors may remain underreported. The implementation of reliable genetic methods in clinical practice will improve the identification process and result in faster and more precise diagnosis of staphylococcal infections. As shown in our review article, in laryngological infections, staphylococci often coexist with other opportunistic and pathogenic bacteria, complicating the identification process. The new genetic diagnostics approach, based on next generation sequencing, may be used for the identification of whole species content in polymicrobial clinical samples. The well-curated and publicly available reference sequence dataset for Staphylococcus species will allow the introduction of this approach in all microbiological laboratories with access to NGS (next-generation sequencing) platforms and may be used in diagnosing laryngological infections $[28,135,136]$.

\section{Concluding remarks}

CoNS are a heterogeneous group of gram-positive bacteria that colonize human or animal skin and mucous membranes and are distributed from these niches into the environment. Although CoNS are present everywhere, they multiply in humans or animals only. Under physiological conditions, CoNS are typical saprophytes, but under exposure to additional conditions, known as infection-facilitating factors, their character changes from saprophytic to pathogenic. Therefore, CoNS are responsible for various infections of different localizations, manifestations or courses. This review article showed that CoNS are widely present in laryngological diseases. Their presence in clinical materials originating 
from laryngological patients presents a new challenge for both clinicians and microbiologists; showing these bacteria in new light. Known in the past as "skin staphylococci", CoNS were interpreted as accompanying bacteria or contamination in diagnostic samples. Today, based on recent reports from advanced microbiological laboratories using molecular diagnostic methods, it is known that CoNS are severe pathogens and require increased infection prevention programs with hygiene discipline in hospitals. Moreover, improved didactic programs are needed to better understand the role of CoNS in laryngological diseases with the primary aim of reducing the number of staphylococcal infections in patients.

\begin{abstract}
Abbreviations
ACME: Arginine catabolic mobile element; agr: Accessory gene regulator; ARS: Acute rhinosinusitis; CoNS: Coagulase-negative staphylococci; CoPS: Coagulase-positive staphylococci; CRS: Chronic rhinosinusitis; FESS: Functional endoscopic sinus surgery; IS: Insertion sequence; MDT-CoNS: Membranedamaging toxins from coagulase-negative staphylococci; NGS: Next-Generation Sequencing; PJI: Prosthetic joint infection; RT: Recurrent tonsillitis; sar: Staphylococcal accessory regulator; SBO: Skull base osteomyelitis; SSSS: Staphylococcal scalded skin syndrome; T: Tonsillitis; TMJ: Temporomandibular joint; TSST-1: Toxic shock syndrome toxin-1.
\end{abstract}

\section{Acknowledgements}

Not applicable.

\section{Authors' contributions}

MM, JM and MKS reviewed previous studies and wrote the manuscript. AS and VS improved and reviewed clinical part of the manuscript. APK investigated the scientific literature in terms of laryngological infections. All authors read and approved the final manuscript.

\section{Funding}

Not applicable.

\section{Availability of data and materials}

Not applicable.

Ethics approval and consent to participate

Not applicable.

\section{Consent for publication}

Not applicable.

\section{Competing interests}

The authors declare that they have no competing interests.

\section{Author details}

${ }^{1}$ MML Medical Centre, Warsaw, Poland. ${ }^{2}$ Clinical Microbiology and Virology, Spirito Santo Hospital, Pescara, PE, Italy. ${ }^{3}$ Department of Microbiology, Faculty of Biochemistry, Biophysics and Biotechnology, Jagiellonian University, Kraków, Poland.

Received: 22 January 2020 Accepted: 25 May 2020

Published online: 04 June 2020

\section{References}

1. Kloos WE, Schleifer KH. Isolation and characterization of staphylococci from human skin. II Descriptions of four new species: Staphylococcus warneri, Staphylococcus capitis, Staphylococcus hominis and Staphylococcus simulans. Int J Syst Bacteriol. 1975;25:62-79.
2. Schleifer KH, Kloos WE. Isolation and characterization of staphylococci from human skin: I Amended descriptions of Staphylococcus epidermidis and S. saprophyticus and descriptions of three new species: Staphylococcus cohnii, Staphylococcus haemolyticus and Staphylococcus xylosus. Int J Syst Bacteriol. 1975;25:50-61.

3. Ogston A. On Abscesses. Rev Infect Dis. 1984;6:122-8.

4. Devriese LA, Devos AH, Beumer J, Maes R. Characterisation of staphylococci isolated from poultry. Poult Sci. 1972;51(2):389-97.

5. Sompolinsky D, Boldur I, Lagziel A, Halperin Y, Caspi E. A series of sepsis due to Staphylococcus aureus after abdominal hysterectomy. Am J Obstet Gynecol. 1979;133(8):931-2.

6. Kloos WE, Bannerman TL. Update on clinical significance of coagulasenegative staphylococci. Clin Microbiol Rev. 1994;7(1):117-40.

7. Becker K, Heilmann C, Peters G. Coagulase-negative staphylococci. Clin Microbiol Rev. 2014;27:870-926. https://doi.org/10.1128/CMR.00109-13.

8. Aly R, Maibach HI, Shinefield HR, et al. Protection of chicken embryos by viridans streptococci against the lethal effect of Staphylococcus aureus. Infect Immun. 1974;9(3):559-63.

9. McCabe WR. Bacterial interference induced in embryonated eggs by staphylococci. J Clin Invest. 1967;46(3):453-62.

10. Międzobrodzki J, Tadeusiewicz R, Heczko PB. Virulence of coagulasenegative Staphylococci for chick embryos. Zbl Bakt Suppl 14, In: The Staphylococci, Ed. Jeljaszewicz J, Fisher Verlag G, Stuttgart, New York $1985 ; 477-480$

11. Międzobrodzki J, Tadeusiewicz R. Staphylococcal dermonecrotic reactions in guinea pigs. Int J Bio Med Comput. 1987;21:67-74.

12. Międzobrodzki J, Tadeusiewicz R. Estimation of staphylococcal pathogenicity for chick embryos. Acta Biol Cracov Ser Bot. 1988;1 (1):1-8.

13. Yu W, Kim HK, Rauch S, Schneewind O, Missiakas D. Pathogenic conversion of coagulase-negative staphylococci. Microbes Infect. 2017;19(2):101-9. https://doi.org/10.1016/j.micinf.2016.12.002.

14. Heilmann C, Ziebuhr W, Becker K. Are coagulase-negative staphylococci virulent? Clin Microbiol Infect. 2019;25(9):1071-80. https://doi. org/10.1016/j.cmi.2018.11.012.

15. Fontana C, Favaro M. Coagulase-positive and coagulase-negative staphylococci in human disease, in Pet-to-Man travelling staphylococci: A world in progress, ed V. Savini (Cambridge, MA: Elsevier), 2018; 25-42. https://doi.org/10.1016/b978-0-12-813547-1.00003-0.

16. Kosecka-Strojek M, Buda A, Międzobrodzki J. Staphylococcal ecology and epidemiology, in Pet-to-Man travelling staphylococci: A World in Progress, ed V. Savini (Cambridge, MA: Elsevier), 2018; 11-24. https://doi. org/10.1016/b978-0-12-813547-1.00002-9.

17. Białecka A, Kasprowicz A. Bacterial flora of respiratory tract infections. Med Dosw Mikrobiol. 1994;46(1-2 Suppl):59-66.

18. Dubois D, Leyssene D, Chacornac JP, et al. Identification of a variety of Staphylococcus species by matrix-assisted laser desorption ionizationtime of flight mass spectrometry. J Clin Microbiol. 2010;48(3):941-5.

19. Huebner J, Goldmann DA. Coagulase-negative staphylococci: role as pathogens. Annu Rev Med. 1999;50:223-36.

20. Grzebyk M, Brzychczy-Włoch M, Piotrowska A, Krzyściak P, Heczko PB, Bulanda M. Phenotypic evaluation of hydrophobicity and the ability to produce biofilm in coagulase-negative staphylococci isolated from infected very-low-birth weight newborns. Med Dow Mikrobiol. 2013;65(3):149-59.

21. Casey AL, Lambert PA, Elliott TS. Staphylococci. Int J Antimicrob Agents. 2007;29(Suppl 3):S23-32.

22. Josse J, Laurent F, Diot A. Staphylococcal adhesion and host cell invasion: Fibronectin-binding and other mechanisms. Front Microbiol. 2017;8:2433. https://doi.org/10.3389/fmicb.2017.02433 (eCollection 2017).

23. Jenkins SN, Okello E, Rossitto PV, Lehenbauer TW, Champagne J, et al. Molecular epidemiology of coagulase-negative Staphylococcus species isolated at different lactation stages from dairy cattle in the United States. Peer J. 2019;7:6749. https://doi.org/10.7717/peerj.6749 (eCollection 2019)

24. GómezSanz E, Ceballos S, RuizRipa L, Zarazaga M, Torres C. Clonally diverse methicillin and multidrug resistant coagulase negative staphylococci are ubiquitous and pose transfer ability between pets and their owners. Front Microbiol. 2019;10:485. https://doi.org/10.3389/fmicb .2019.00485 (eCollection 2019). 
25. Górecka A, Nowiński A, Augustynowicz-Kopeć E. Microbiom of the lung. Pneumol Alergol Pol. 2014;82:481-5.

26. Malinowska M, Tokarz-Deptuła B, Deptuła W. The respiratory tract micro biota in physiological and pathological conditions. Post Mikrobiol. 2016:55(3):279-83.

27. Parte AC. LPSN-list of prokaryotic names with standing in nomenclature (bacterio.net), 20 years on. Int J Syst Evol Microbiol. 2018;68:1825-9.

28. Kosecka-Strojek M, Sabat AJ, Akkerboom V, Becker K, van Zanten E, et al. Development and validation of a reference data set for assigning staphylococcus species based on next-generation sequencing of the 16S-23S rRNA region. Front Cell Infect Microbiol. 2019;9:278. https://doi. org/10.3389/fcimb.2019.00278.

29. Bonar E, Międzobrodzki J,Władyka B. The Staphylococcal coagulases. In: Pet-to-Man travelling staphylococci. A world in progress, ed V. Savini (Cambridge, MA: Elsevier), 2018; 95-102. https://doi.org/10.1016/b9780-12-813547-1.00007-8

30. Lepidi A. Staphylococcal lipases. In: Pet-to-man travelling staphylococci. A world in progress, ed V. Savini (Cambridge, MA: Elsevier), 2018; 147-159. https://doi.org/10.1016/b978-0-12-813547-1.00012-1.

31. Międzobrodzki J, Naidu AS, Watts JL, Ciborowski P, Palm K, Wadström T. Effect of milk on fibronectin and collagen type I binding to Staphylococcus aureus and coagulase-negative staphylococci isolated from bovine mastitis. J Clin Microbiol. 1989;27(3):540-4.

32. Stach N, Kaszycki P, Władyka B, Dubin G. Extracellular proteases of Staphylococcus spp. In: Pet-to-man travelling staphylococci. A world in progress, ed V. Savini (Cambridge, MA: Elsevier), 2018; 135-145. https:// doi.org/10.1016/b978-0-12-813547-1.00011-x.

33. Kreiswirth BN, Schlievert PM, Novick RP. Evaluation of coagulase-negative staphylococci for ability to produce toxic shock syndrome toxin 1. J Clin Microbiol. 1987;25:2028-9.

34. Bukowski M, Władyka B, Dubin A, Dubin G. The Staphylococcal exfoliative toxins in: Pet-to-Man travelling Staphylococci. A world in progress, ed V. Savini (Cambridge, MA: Elsevier), 2018; 127-133. https://doi. org/10.1016/b978-0-12-813547-1.00010-8.

35. Nawrotek P, Karakulska J, Fijałkowski K. The Staphylococcal Panton-Valentine leukocidin (PVL). In: Pet-to-man travelling staphylococci. A world in progress, ed V. Savini (Cambridge, MA: Elsevier), 2018; 117-125.

36. Pontieri A. Staphylococcal Lipases. In: Pet-to-man travelling staphylococci. A World in Progress, ed V. Savini (Cambridge, MA: Elsevier), 2018; 147-159. https://doi.org/10.1016/b978-0-12-813547-1.00008-x.

37. Peters $G$, Locci R, Pulverer $G$. Adherence and growth of coagulasenegative staphylococci on surfaces of intravenous catheters. J Infect Dis. 1982;146:479e82.

38. Arrecubieta C, Asai T, Bayern M, Loughman A, Fitzgerald JR, Shelton CE, et al. The role of Staphylococcus aureus adhesins in the pathogenesis of ventricular assist device-related infections. J Infect Dis. 2006;193:1109e19.

39. Vuong C, Voyich JM, Fischer ER, Braughton KR, Whitney AR, DeLeo FR, et al. Polysaccharide intercellular adhesin (PIA) protects Staphylococcus epidermidis against major components of the human innate immune system. Cell Microbiol. 2004;6(3):269-75.

40. Arciola CR, Campoccia D, Montanaro L. Implant infections: adhesion, biofilm formation and immune evasion. Nat Rev Microbiol. 2018;16(7):397-409. https://doi.org/10.1038/s41579-018-0019-y.

41. Ziebuhr W, Heilmann C, Gotz F, Meyer P, Wilms K, et al. Detection of the intercellular adhesion gene cluster (ica) and phase variation in Staphylococcus epidermidis blood culture strains and mucosal isolates. Infect Immun. 1997;65(3):890-6.

42. Frebourg NB, Lefebvre S, Baert S, Lemeland JF. PCR-Based assay for discrimination between invasive and contaminating Staphylococcus epidermidis strains. J Clin Microbiol. 2000;38:877e80.

43. Galdbart JO, Allignet J, Tung HS, Ryden C, El Solh N. Screening for Staphylococcus epidermidis markers discriminating between skin-flora strains and those responsible for infections of joint prostheses. J Infect Dis. 2000;182:351e5

44. Barbier F, Lebeaux D, Hernandez D, Delannoy AS, Caro V, François P, et al. High prevalence of the arginine catabolic mobile element in carriage isolates of methicillin-resistant Staphylococcus epidermidis. J Antimicrob Chemother. 2011;66:29e36.

45. Bukowski M, Piwowarczyk R, Madry A, Zagorski-Przybylo R, Hydzik $\mathrm{M}$, Wladyka B. Prevalence of antibiotic and heavy metal resistance determinants and virulence-related genetic elements in plasmids of Staphylococcus aureus. Front Microbiol. 2019. https://doi.org/10.3389/ fmicb.2019.00805.

46. McCarthy AJ, Loeffler A, Witney AA, Gould KA, Lloyd DH, Lindsay JA. Extensive horizontal gene transfer during Staphylococcus aureus COcolonization in vivo. Genome Biol Evol. 2014;6(10):2697-708. https:// doi.org/10.1093/gbe/evu214.

47. Bosch T, Witteveen S, Haenen A, Landman F, Schouls LM. Next-generation sequencing confirms presumed nosocomial transmission of livestock-associated methicillin-resistant Staphylococcus aureus in the Netherlands. Appl Environ Microbiol. 2016;82(14):4081-9. https://doi. org/10.1128/AEM.00773-16.

48. Águila-Arcos S, Álvarez-Rodríguez I, Garaiyurrebaso O, Garbisu C, Grohmann E, Alkorta I. Biofilm-forming clinical Staphylococcus isolates harbor horizontal transfer and antibiotic resistance genes. Front Microbiol. 2018;2017(8):2017. https://doi.org/10.3389/fmicb.2017.02018 (eCollection 2017)

49. Wójcik K. Regulation of virulence factors gene expression in Staphylococcus aureus. Post Mikrobiol. 1997;24(8):77-85.

50. Arya R, Princy SA. An insight into pleiotropic regulators Agr and Sar: molecular probes paving the new way for antivirulent therapy. Future Microbiol. 2013;8(10):1339-53. https://doi.org/10.2217/fmb.13.92.

51. Arya R, Princy SA. Exploration of modulated genetic circuits governing virulence determinants in Staphylococcus aureus. Indian J Microbiol. 2016;56(1):19-27. https://doi.org/10.1007/s12088-015-0555-3.

52. Baron S, editor. Medical Microbiology. 4th edition. Galveston (TX): University of Texas Medical Branch at Galveston; 1996. https://www.ncbi. nlm.nih.gov/books/NBK7627.

53. Akiyama K, Karak M, Mori N. Evaluation of adult potas puffy tumor: our five cases and 27 literature cases. Laryngoscope. 2012;122(11):2382-8.

54. Jeannon JP, Orabi A, Manganaris A, Simo R. Multiresistant Staphylococcus aureus infection as a causative agent of fistula formation following total laryngectomy for advanced head \& neck cancer. Head Neck Oncol. 2010;2:14. https://doi.org/10.1186/1758-3284-2-14.

55. Brzychczy-Włoch M, Borszewska-Kornecka M, Gulczyńska E, Wójkowska-Mach J, Sulik M, Grzebyk M, et al. Prevalence of antibiotic resistance in multi-drug resistant coagulase-negative staphylococci isolated from invasive infection in very low birth weight neonates in two Polish NICUs. Ann Clin Microbiol Antimicrob. 2013. https://doi. org/10.1186/1476-0711-12-41.

56. Drago L, Cappelletti L, Lamartina C, Berjano P, Mattina M, DeVecchi E. Colonization by methicillin resistant staphylococci of nares and skin in healthcare workers: a pilot study in spinal surgeries. Int J Care Injured. 2015:46(S8):S77-80.

57. Rogers KL, Fey PD, Rupp ME. Coagulase-negative staphylococcal infections. Infect Dis Clin North Am. 2009;23(1):73-98. https://doi. org/10.1016/j.idc.2008.10.001.

58. Natsis NE, Cohen PR. Coagulase-negative Staphylococcus skin and soft tissue infections. Am J Clin Dermatol. 2018;19(5):671-7. https://doi. org/10.1007/s40257-018-0362-9.

59. Lalani T, Kanafani ZA, Chu VH, Moore L, Corey GR, Pappas P, et al. International collaboration on endocarditis merged database study group. Prosthetic valve endocarditis due to coagulase-negative staphylococci: findings from the international collaboration on endocarditis merged database. Eur J Clin Microbiol Infect Dis. 2006:25(6):365-8.

60. García Mària C, Cervera C, Pericàs JM, Castañeda X, Armero Y, Soy D, Hospital clinic endocarditis study group, et al. Epidemiology and prognosis of coagulase-negative staphylococcal endocarditis: impact of vancomycin minimum inhibitory concentration. PLOS ONE. 2015;10(5):e0125818. https://doi.org/10.1371/journal.pone.0125818 (eCollection 2015)

61. Vogkou CT, Vlachogiannis NI, Palaiodimos L, Kousoulis AA. The causative agents in infective endocarditis: a systematic review comprising 33,214 cases. Eur J Clin Microbiol Infect Dis. 2016;35(8):1227-45. https:// doi.org/10.1007/s10096-016-2660-6.

62. Bachert C, Pawankar R, Zhang L, Bunnag C, Fokkens WJ, Hamilos DL, et al. ICON: chronic rhinosinusitis. World Allergy Organ J. 2014;7(1):25. https://doi.org/10.1186/1939-4551-7-25.

63. Długaszewska J, Leszczyńska M, Lenkowski M, Tatarska A, PastusiakT, Szyfter W. The pathophysiological role of bacterial biofilms in chronic 
sinusitis. Eur Arch Othorhinol. 2015. https://doi.org/10.1007/s0040 5-015-3650-5.

64. Anderson M, Stokken J, Sanford T, Aurora R, Sindvani R. A systematic review of the sinonasal microbiome in chronic rhinosinusitis. Am J Rhinol Allergy. 2016;30(3):161-6.

65. Manes RP, Batra PS. Bacteriology and antibiotic resistance in chronic rhinosinusitis. Facial Plast Surg Clin N Am. 2012;20:87-91.

66. Zhang Z, Adappa ND, Lautenbach E, Chiu AG, Doghramji LJ, Cohen NA, Palmer JN. Coagulase-negative staphylococcus culture in chronic rhinosinusitis. Int Forum Allergy Rhinol. 2015;5(3):204-13.

67. Yildirim A, Oh C, Erdem H, Kunt T. Bacteriology in patients with chronic sinusitis who have been medically and surgically treated. Ear Nose Throat J. 2004;83(12):836-8.

68. Li H, Xu L, Wang J, et al. Conversion of Staphylococcus epidermidis strains from commensal to invasive by expression of the ica locus encoding production of biofilm exopolysaccharide. Infect Immun 2005;73(5):3188-91.

69. Thanasumpun T, Batra PS. Endoscopically-derived bacterial cultures in chronic rhinosinusitis: a systematic review. Am J Otolaryngol. 2015:36:686-91.

70. Bhattacharyya N, Kepnes $L$ J. The microbiology of recurrent rhinosinusitis after endoscopic sinus surgery. Arch Otolaryngol Head Neck Surg. 1999;125:1117-20.

71. Klossek JM, Dubreuil L, Richet $\mathrm{H}$, et al. Bacteriology of chronic purulent secrations in chronic rhinosinusitis. J Laryngol Otol. 1998;112:1162-6.

72. Granville L, Chirala M, Cernoch P, Ostrowski M, Truong LD. Fungal sinusitis: histologic spectrum and correlation with culture. Hum Pathol. 2004;35(4):474-81.

73. Montone KT. Differential diagnosis of necrotizing sinonasal lesions. Arch Pathol Lab Med. 2015;139:1508-14.

74. Wellinghansen N, Sing A, Kern WV, Perner S, Marre R, Rentschler J. A fatal case of necrotizing sinusitis due to toxigenic Corynebacterium ulcerans. Int J Med Microb. 2002;292(1):59-63.

75. Matthews PC, Lazarus R, Protheroe A, Milford C, Bowler IC. J Acute necrotizing sinusitis caused by Staphylococcus lugdunensis. J Clin Microbiol. 2011;49(7):2740-2.

76. You YO, Kim KJ, Min BN, Chung CP. Staphylococcus lugdunensis-a potential patogen in oral infections. Oral Surg Oral Med Oral Pathol Oral Radiol Endod. 1999;88:297-302.

77. Thomas S, Hoy C, Capper R. Osteomyelitis of the ear canal caused by Staphylococcus lugdunensis. J Infect. 2006;53:e227-9.

78. Goyal M, Javerliat F, Palmieri M, Mirande C, van Wamel W, et al. Genomic evolution of Staphylococcus aureus during artificial and natural colonization of the human nose. Front Microbiol. 2019;10:1525. https://doi. org/10.3389/fmicb.2019.01525.

79. Kaspar U, Kriegeskorte A, Schubert T, Peters G, Rudack C, et al. The culturome of the human nose habitats reveals individual bacterial fingerprint patterns. Environ Microbiol. 2016;18(7):2130-42. https://doi. org/10.1111/1462-2920.12891.

80. Międzobrodzki J, Naidu AS, Watts JL, Ciborowski P, Palm K, Wadstrom T. Influence of milk on fibronectin and collagen type-l binding to Staphylococcus aureus and coagulase-negative Staphylococci isolated from bovine mastitis. J Clin Microbiol. 1989:27:540-4

81. Jaworek R, Pawliczak R, Międzobrodzki J. Recent opinions on the role of acidophilic granulocytes in mechanisms of immunological defense and in pathogenesis of selected human diseases. Folia Med Cracov. 2008;49(3-4):13-22.

82. Moy BT, Forouhar F, Kuo CL, Devers TJ. Endoscopic features of mucous cap polyps: a way to predict serrated polyps. Clin Endosc. 2018:51(4):368-74. https://doi.org/10.5946/ce.2017.155.

83. Bezerra TF, Padua FG, Gebrim EM, Sladiva PH, Voegels RL. Biofilm in chronic rhinisinusitis with nasal polyps. Otolaryngol Head Neck Surg. 2011;144(4):612-6.

84. Liu Q, Lu X, Bo M, Qing H, Wang X, Zhang L. The microbiology of chronic rhinosinusitis with and without nasal polyps. Acta Otolaryngol. 2014:134:1251-8.

85. Wei HZ, Li YC, Wang XD, Lu XX, Hu CH, He S, et al. The microbiology of chronic rhinosinusitis with and without nasal polyps. Eur Arch OtoRhino-Laryngol. 2018;275:1439-47.
86. Heczko PB, Hoeffler U, Kasprowicz A, Pulverer G. Quantitative studies of the flora of nasal vestibule in relation to nasal carriage of Staphylococcus aureus. J Med Microbiol. 1981;14(3):233-41.

87. Egert $M$, Simmering R. The microbiota of the human skin. Adv Exp Med Biol. 2016;902:61-81. https://doi.org/10.1007/978-3-319-31248-4_5.

88. Belkaid Y, Segre JA. Dialogue between skin microbiota and immunity. Science. 2014;346(6212):954-9. https://doi.org/10.1126/science.12601 44.

89. Somerville $\mathrm{DA}$. The normal flora of the skin in different age groups. $\mathrm{Br} \mathrm{J}$ Dermatol. 1969;81(4):248-58.

90. Dubin G, Chmiel D, Mak P, Rachwalska M, Rzychoń M, Dubin A. Molecular cloning and biochemical characterization of proteases from Staphylococcus epidermidis. Biol Chem. 2001;382:1575-82.

91. Międzobrodzki J, Kaszycki P, Białecka A, Kasprowicz A. Proteolytic activity of Staphylococcus aureus strains isolated from the colonization of patients with acute-phase atopic dermatitis. Eur J Clin Microbiol Infect Dis. 2002;21(4):269-76.

92. Conlan S, Mijares L, NISC Comparative Sequencing Program, Becker J, Blakesley RW, Bouffard GG, Brooks S, Coleman H, et al. Staphylococcus epidermidis pan-genome sequence analysis reveals diversity of skin commensal and hospital infection-associated isolates. Genome Biol. 2012;13(7):R64. https://doi.org/10.1186/gb-2012-13-7-r64.

93. Becker K, Lahom NA, Fegeler W, Proctor RA, Peters G, von Eiff C. Fouriertransform infrared spectroscope analysis as a powerful tool for studying the dynamic changes in Staphylococcus aureus small colony variants. $J$ Clin Microbiol. 2006;44:3274-8.

94. Lee YL, Cesario T, Tran C, Stone G, Thrupp L. Nasal colonization by methicillin-resistant coagulase-negative Staphylococcus in commonly skilled nursing facility patients. Amer I Infect Control. 2000;28(3):269-72.

95. Kozioł-Montewka M, Szczepanik A, Baranowicz I, Jóźwiak L, Książek A, Kaczor D. The investigation of Staphylococcus aureus and coagulasenegative staphylococci nasal carriage among patients undergoing haemolysis. Microbiol Res. 2006;161(4):281-7.

96. Staphylococcal infections. Merck Manual Professional Version. http:// www.merckmanuals.com/professional/infectious-diseases/gram-posit ive-cocci/staphylococcal-infections. Accessed Apr. 06, 2020.

97. Hayden MK, Lolans K, Haffenreffer K, Avery TR, Kleinman K, et al. Chlorhexidine and mupirocin susceptibility of methicillin-resistant Staphylococcus aureus isolates in the REDUCE-MRSA. Trial I Clin Microbiol. 2016;54(11):2735-42.

98. Rudresh MS, Ravi GS, Motagi A, Alex AM, Sandhya P. Prevalence of mupirocin resistance among Staphylococci, its clinical significance and relationship to clinical use. J Lab Physicians. 2015;7(2):103-7. https://doi. org/10.4103/0974-2727.163127.

99. Al-Ani MZ, Davies SJ, Gray RJ, Sloan P, Glenny AM. Stabilisation splint therapy for temporomandibular pain dysfunction syndrome. Cochrane Database Syst Rev. 2004. https://doi.org/10.1002/14651858.CD002778. pub2.

100. Hyung-Mo K, Tae-Wan K, Ju-Hong H, Dong-Joo L, Na-Rae P, Seung-II SJ. Infection of the temporomandibular joint: a report of three cases. J Korean Assoc Oral Maxillofac Surg. 2011;37(6):510-4. https://doi. org/10.5125/jkaoms.2011.37.6.510

101. Ouanounou A, Goldberg M, Haas DA. Pharmacotherapy in temporomandibular disorders: a Review. J Can Dent Assoc. 2017;83:h7.

102. Kessler B, Sendi P, Graber P, Krupp M, Zwicky L, Hintermenn B, et al. Risk factors for periprosthetic ankle joint infection: a case-control study. J Bone Joint Surg. 2012;94(20):1871-6.

103. Chisnoiu AM, Picos AM, Popa S, Chisnoiu PD, Lascu L, Picos A, et al. Factors involved in the etiology of temporomandibular disorders-a literature review. Clujul Med. 2015;88(4):473-8. https://doi.org/10.15386 /cjmed-485.

104. Chidzonga MM. Temporomandibular joint ankylosis: review of thirty two cases. Br J Oral Surg. 1999:37(2):123-6.

105. Lupton DE. Psychological aspects of temporomandibular joint dysfunction. J Am Dent Assoc. 1969:79(1):131-6.

106. Kim T, Kandiah S, Patel M, Rab S, Wong J, et al. Risk factors for kidney injury during vancomycin and piperacillin/tazobactam administration, including increased odds of injury with combination therapy. BMC Res Notes. 2015;8:579. https://doi.org/10.1186/s13104-015-1518-9. 
107. Winters SE. Staphylococcus infection of the temporomandibular joint. Oral Surg Oral Med Oral Pathol Oral Radiol. 1955;8(2):148-50.

108. Malachovsky I, Janickova M, Stasko J, Kasaj M, Sadlonova V, Novakova E, et al. Pseudomonas infection of the temporomandibular joint (TMJ) Health and Public Health Issues. Acta Medica Martiniana. 2017;17(1):339. https://doi.org/10.1515/acm-2017-0005.

109. Butt HL, Dunstan RH, McGregor NR, Roberts TK, Zerbes M, Klineberg TJ. An association of membrane-damaging toxins from coagulase-negative staphylococci and chronic orofacial muscle pain. J Med Microbiol. 1998:47:577-84

110. Tevell S, Hellmark B, Nilsdotter-Augustiansson A, Soderquist B. Staphylococcus capitis isolated from prosthetic joint infections. Eur J Clin Microbiol Infec Dis. 2017;36:115-22.

111. McGregor NR, Zerbes M, Niblett SH, Dunstan RH, Roberts TK, Butt HL, et al. Coagulase-negative Staphylococcal membrane-damaging toxins, pain intensity and metabolic changes in temporomandibular disorder patients with chronic muscle pain. J Orofacial Pain. 2003;17(2):125-32.

112. Metcalf $L N, M c G r e g o r ~ N R$, Roberts TK. Membrane damaging toxins from coagulase-negative Staphylococcus are associated with self-reported temporomandibular disorders (TMD) in patients with chronic fatigue syndrome. J Chronic Fatigue Syndr. 2004;12(3):25-43.

113. Guo G, Wang J, You Y, Tan J, Shen H. Distribution characteristics of Staphylococcus spp. in different phases of periprosthetic joint infection: a review. Exp Therapeutic Med. 2017;13:2599-608.

114. Uckay L, Harbarth S, Ferry T, Lubbeke A, Emonet S, Hoffmeyer P, et al. Methicillin resistance in orthopaedic coagulase-negative staphylococcal infections. J Hosp Infect. 2011;79:248-53.

115. Triffault-Fillit C, Ferry T, Laurent F, Pradat P, Dupieux C, Lyon BJI Study Group, et al. Microbiologic epidemiology depending on time to occurrence of prosthetic joint infection: a prosoective cohort study. Clin Microbiol Infect. 2019:25(3):353-8.

116. Armstrong DG, Lanthier J, Lelievre P, Edelson GW. Methicillin-resistant coagulase-negative staphylococcal osteomyelitis and its relationship to broad-spectrum oral antibiosis in a predominantly diabetic population. J Foot Ankle Surg. 1995;34(6):563-6.

117. Loiez C, Wallet F, Pischedda P, Renaux E, Senneville E, Mehdi N, et al. First case of osteomyelitis caused by Staphylococcus pettenkoferi. J Clin Microbiol. 2007:45(3):1067-71

118. Johnson AK, Batra PS. Central skull base osteomyelitis: an emerging clinical entity. Laryngoscope. 2014;124(5):1083-7. https://doi. org/10.1002/lary.24440.

119. Zimmerli W, Widmer AF, Blatter M, Frei R, Ochsner PE, Foreign-Body Infection (FBI) Study Group. Role of rifampin for treatment of orthopedic implant-related staphylococcal infections: a randomized controlled trial. JAMA. 1998;279(19):1537-41.

120. Wilk I, Ekiel A, Kłuciński P, Krzysztoń-Russjan J, Martirosian G. Characterization of coagulase-negative staphylococci isolated from cases of ostitis and osteomyelitis. Pol J Microbiol. 2006;55(3):175-8

121. Haeffs TH, Scott CA, Cambell TH, Chen Y, August M. Acute and chronic suppurative osteomyelitis of the jaws: a 10-years review and assessment of treatment outcome. J Oral Maxillofac Surg. 2018;76(12):2552-8.

122. Deepak S, Samant SA, Urhekar AD. Study of coagulase positive and negative Staphylococci in clinical samples. Indian J Med Sci. 1999;53(10):425-8.

123. Giedrys-Kalemba S, Hałasa J, Podkowińska I. Persistance of Staphylococcus aureus in the pharynx of children with chronic tonsilitis treated with autovaccine. Pediatr Pol. 1985;60:761-7.

124. Thattil SS, Santosh S, Ajith TA. Staphylococcus associated acute throat infection among children presented to a tertiary care hospital. Int J Res Med Sci. 2018:6(10):3287-92.
125. Katkowska M, Garbacz K, Stromkowski J. Staphylococcus aureus isolated from tonsillectomized adult patients with recurrent tonsillitis. APMIS. 2017:125:46-51.

126. Zautner AE, Krause M, Stropahl G, Holtfreter S, Frickmann H, Maletzki C, et al. Intracellular persisting Staphylococcus aureus is the major pathogen in recurrent tonsilitis. PLoS One. 2010;5(3):e9452. https://doi. org/10.1371/journal.pone.0009452.

127. Kuhn JJ, Brook I, Walters CL, Church LW, Bianchi DA, Thompson DH. Quantitative bacteriology of tonsils removed from children with tonsillitis hypertrophy and recurrent tonsillitis with and without hypertrophy. Ann Otol Rhinol Laryngol. 1995;104(8):646-52.

128. Jayashima VL, Vinodkumar CS, Raghukumar KG, Basavarajappa KG Surface tonsillar bacteria versus deep tonsillar bacteria in tonsillitis. J. Pub Health Med Res. 2013;1(2):92-4.

129. Abraham ZS, Bazilia J, Kahinga AA, Manyahi J, Ntunaguzi D, Massawe ER. Patients attending otorhinolaryngology department at Muhimbili National Hospital, Dar es Salam—Tanzania. Med J Zambia. 2019:46(1):33-40

130. Miszke A, Kasprowicz A, Heczko PB. Quantitative analysis of aerobic and microaerophilic bacterial flora of palatine tonsils in patients with recurrent tonsillitis. Otolaryngol Pol. 1987;41:396-401.

131. Ayeni FA, Andersen C, Nørskov-Lauritsen N. Comparison of growth on mannitol salt agar, matrix-assisted laser desorption/ionization timeofflight mass spectrometry, VITEK 2 with partial sequencing of $16 \mathrm{~S}$ rRNA gene for identification of coagulase-negative staphylococci. Microb Pathog. 2017;105:255-9. https://doi.org/10.1016/j.micpath.2017.02.034.

132. Becker K, Harmsen D, Mellmann A, Meier C, Schumann P, Peters G, et al. Development and evaluation of a qualitycontrolled ribosomal sequence database for 165 ribosomal DNA-based identification of Staphylococcus species. J Clin Microbiol. 2004;42:4988-95. https://doi. org/10.1128/JCM.42.11.4988-4995.2004.

133. Kosecka-Strojek M, Ilczyszyn WM, Buda A, Polakowska K, Murzyn K, et al. Multiple-locus variable-number tandem repeat fingerprinting as a method for rapid and cost-effective typing of animal-associated Staphylococcus aureus strains from lineages other than sequence type 398. J Med Microbiol. 2016;65(12):1494-504. https://doi.org/10.1099/ jmm.0.000378.

134. Lisowskałysiak K, Kosecka-Strojek M, Białecka J, Kasprowicz A, Garbacz $K$, et al. New insight into genotypic and phenotypic relatedness of Staphylococcus aureus strains from human infections or animal reservoirs. Pol J Microbiol. 2019;68(1):93-104. https://doi.org/10.21307/ pjm-2019-011.

135. Sabat AJ, van Zanten E, Akkerboom V, Wisselink G, van Slochteren K, de Boer RF, et al. Targeted next-generation sequencing of the 16S-23S rRNA region for culture-independent bacterial identification-increased discrimination of closely related species. Sci Rep. 2017;7:3434. https:// doi.org/10.1038/s41598-017-03458-6.

136. Kosecka-Strojek M, Sabat AJ, Akkerboom V, Kooistra-Smid AMDM, Miedzobrodzki J, Friedrich AW. Development of a reference data set for assigning Streptococcus and Enterococcus species based on next generation sequencing of 16S-23S rRNA region. Antimicrob Resist Infect Control. 2019;8:178. https://doi.org/10.1186/s13756-019-0622-3.

\section{Publisher's Note}

Springer Nature remains neutral with regard to jurisdictional claims in published maps and institutional affiliations. 